\title{
Resistance to type 1 diabetes induction in 12-lipoxygenase knockout mice
}

\author{
David Bleich, ${ }^{1}$ Songyuan Chen, ${ }^{1}$ Brian Zipser, ${ }^{1}$ Duxin Sun, ${ }^{2}$ Colin D. Funk, ${ }^{2}$ \\ and Jerry L. Nadler ${ }^{1}$ \\ ${ }^{1}$ Division of Diabetes, Endocrinology, and Metabolism, City of Hope National Medical Center, Duarte, California 91010, USA
${ }^{2}$ Center for Experimental Therapeutics, University of Pennsylvania, Philadelphia, Pennsylvania 19104, USA \\ Address correspondence to: Jerry L. Nadler, Division of Diabetes, Endocrinology, and Metabolism, City of Hope National Medical \\ Center, 1500 E. Duarte Road, Duarte, California 91010, USA. Phone: (626) 359-8111, ext. 2689; Fax: (626) 301-8212; \\ E-mail: jnadler@smtplink.coh.org. \\ Received for publication September 16, 1998, and accepted in revised form April 2, 1999.
}

Leukocyte 12-lipoxygenase (12-LO) gene expression in pancreatic $\beta$ cells is upregulated by cytotoxic cytokines like IL-1 $\beta$. Recent studies have demonstrated that 12-LO inhibitors can prevent glutamateinduced neuronal cell death when intracellular glutathione stores are depleted. Therefore, 12-LO pathway inhibition may prevent $\beta$-cell cytotoxicity. To evaluate the role of 12 -LO gene expression in immune-mediated islet destruction, we used 12-LO knockout (12-LO KO) mice. Male homozygous 12-LO KO mice and control C57BL/ 6 mice received 5 consecutive daily injections of low-dose streptozotocin to induce immunemediated diabetes. Fasting serum glucose and insulin levels were measured at 7 -day intervals, and the mice were followed up for 28 days. 12-LO KO mice were highly resistant to diabetes development compared with control mice and had higher serum insulin levels on day 28. Isolated pancreatic islets were treated with IL$1 \beta$, TNF- $\alpha$, and IFN- $\gamma$ for 18 hours. Glucose-stimulated insulin secretion in cytokine-treated islets from C57/BL6 mice decreased 54\% from that of untreated islets. In marked contrast, the same cytokine mix led to only a $26 \%$ decrease in islets from 12 -LO KO mice. Furthermore, cytokine-induced 12 -hydroxyeicosatetraenoic acid (12-HETE) production was absent in 12-LO KO islets but present in C57/BL6 islets. Isolated peritoneal macrophages were stimulated for 48 hours with IFN- $\gamma+$ LPS and compared for nitrate/nitrite generation. 12-LO KO macrophages generated 50\% less nitrate/nitrite when compared with C57BL/6 macrophages. In summary, elimination of leukocyte $12-\mathrm{LO}$ in mice ameliorates low dose streptozotocin-induced diabetes by increasing islet resistance to cytokines and decreasing macrophage production of nitric oxide.

J. Clin. Invest 103:1431-1436 (1999).

\section{Introduction}

The leukocyte 12-lipoxygenase (12-LO) gene is expressed in pancreatic $\beta$ cells and macrophages. Products of the 12-LO enzyme are proinflammatory and may be involved in immune-mediated conditions, but formal proof of this hypothesis is lacking. Leukocyte 12LO is preferentially expressed over 5- and 15-lipoxygenase in pancreatic $\beta$ cells and may be involved in cytokine-mediated $\beta$-cell damage through generation of the lipid hydroperoxide 12-hydroperoxyeicosatetraenoic acid (12-HPETE) (1-7). Reduction of 12-HPETE to 12hydroxyeicosatetraenoic acid (12-HETE) is facilitated by the enzyme glutathione peroxidase, and recent work has demonstrated that 12 -LO inhibitors can prevent glutamate-induced neuronal cell death when intracellular glutathione stores are depleted (8). Both neuronal cell death and peroxide generation required $12-\mathrm{LO}$ activity in this model and were prevented by treatment with a lipoxygenase inhibitor, baicalein $(10 \mu \mathrm{M})$. Furthermore, the proinflammatory cytokine IL- $1 \beta$ was shown to increase 12 -LO product formation in pancreatic islets $(9,10)$, whereas nordihydroguaiaretic, a lipoxygenase inhibitor, protected rat islet cells from cytokine-induced destruction (11). Given that 12-HPETE and/or other 12LO products may damage pancreatic $\beta$ cells through lipid peroxidation, it is possible that inhibition of the 12 -LO pathway may protect pancreatic $\beta$ cells from cytotoxic conditions.

To test this hypothesis, we administered low-dose streptozotocin (STZ) to 12-LO knockout (12-LO KO) mice and genetic controls to evaluate the development of diabetes. In addition, we isolated pancreatic islets and tested them for sensitivity to cytokine-induced dysfunction. We also evaluated the capacity of macrophages to generate nitric oxide (NO) and superoxide when stimulated. We chose the low dose STZ-induced diabetic model because previous studies have demonstrated that $\beta$-cell destruction is mediated in part by generation of free radicals and lipid hydroperoxides as well as by immune activation $(12,13)$. 12-LO KO mice were generated by homologous recombination in embryonic stem cells, as described previously (14).

In the present study, we found that 12 -LO KO mice were significantly more resistant to STZ-induced diabetes than were $\mathrm{C} 57 \mathrm{BL} / 6$ controls and that islets purified from 12-LO KO mice were protected from cytokine-induced dysfunction. Furthermore, macrophages from 12 -LO KO mice generated $\sim 50 \%$ of the nitrate/nitrite compared with macrophages from control C57BL/6 mice. 


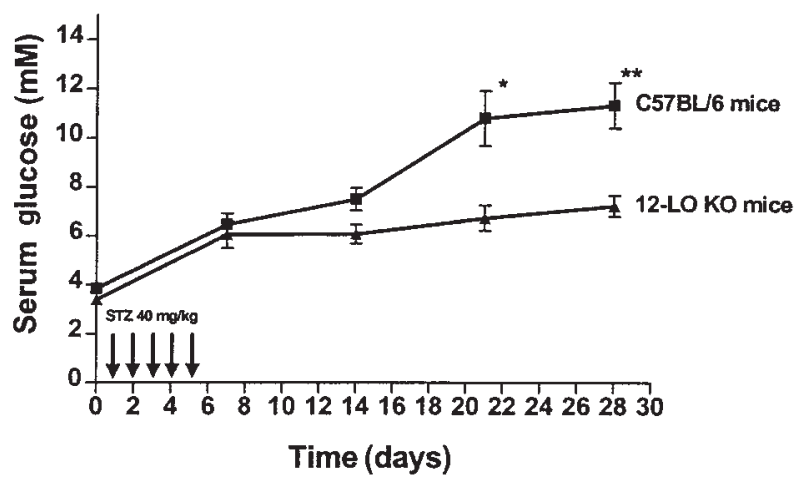

Figure 1

Serum glucose levels in low dose STZ-treated 12-LO KO and C57BL/6 mice. Eight 12-LO KO and $12 \mathrm{C} 57 \mathrm{BL} / 6$ mice received $40 \mathrm{mg} / \mathrm{kg}$ of STZ for 5 consecutive days as shown. The mean fasting serum glucose \pm SEM for each group of mice is shown at each time point. 12-LO KO mice were significantly more resistant to STZ-induced diabetes than C57BL/ 6 control mice. ${ }^{*} P=0.01$ vs. 12 -LO KO. ${ }^{*} P=0.003$ vs. 12 -LO KO.

Therefore, disruption of the leukocyte 12 -LO gene markedly reduces STZ-induced diabetes. The protective mechanisms appear to be due to resistance to cytokineinduced islet dysfunction and reduced macrophage release of NO.

\section{Methods}

Glucose determinations were made with a One Touch Profile (Lifescan Inc., Milpitas, California, USA) and validated with a glucose analyzer (Yellow Springs Instrument, Yellow Springs, Ohio, USA). Mouse insulin was measured with mouse-specific insulin RIA kits (Linco Research Inc., St. Charles, Missouri, USA). Anti-12-HETE antibody was purchased from PerSeptive Biosystems (Framingham, Massachusetts, USA). IL-1 $\beta$, TNF- $\alpha$, and IFN- $\gamma$ were purchased from R\&D Systems Inc. (Minneapolis, Minnesota, USA). Cytochrome $c$ was obtained from Sigma Chemical Co. (St. Louis, Missouri, USA). Protein determinations were performed according to the method of Bradford using Sigma Brilliant Blue G for detection and Sigma BSA Fraction $\mathrm{V}$ as a standard.

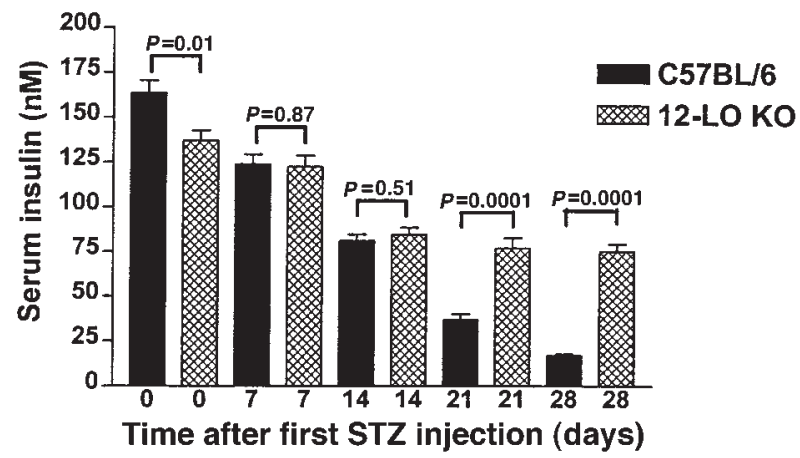

Figure 2

Serum insulin levels in low dose STZ-treated 12-LO KO and C57BL/ 6 mice. 12-LO KO mice demonstrated a $45 \%$ decrease in insulin levels from day 0 to day 28 , whereas C57BL/ 6 mice had a $90 \%$ decrease in insulin levels after low-dose STZ treatment. A statistically significant difference in insulin levels between 12-LO KO and C57BL/ 6 mice is seen on days 21 and 28 .
Generation of 12- $\mathrm{LO} \mathrm{KO}$ mice. The generation of $12-\mathrm{LO} \mathrm{KO}$ mice has been described previously (14). The mice were backcrossed to the C57BL/6 genetic background 11 times (>99\% C57BL/6). All animal studies were performed in accordance with guidelines set forth by the Research Animal Care Committees of City of Hope National Medical Center and University of Pennsylvania.

Low dose STZ-induced diabetes. Male C57BL/6 and 12-LO KO mice aged 12-16 weeks were used in this study. Mice received $40 \mathrm{mg} / \mathrm{kg}$ of STZ intraperitoneally on 5 consecutive days between 0900 and 1000 hours. The mice were housed in a temperature-controlled room with 12 -hour light/12-hour dark cycles. Mice were given free access to water and standard laboratory chow during these studies. Blood was obtained weekly from the retro-orbital plexus via capillary tube and used for glucose and insulin determinations. All specimens were obtained after an overnight fast. Mice were followed up for a total of 28 days, at which time they were sacrificed. We defined diabetes as fasting glucose $>7.8 \mathrm{mM}(\sim 140 \mathrm{mg} / \mathrm{dL})$.

Purification of mouse islets and islet studies. Mice were sacrificed with $\mathrm{CO}_{2}$ gas, and pancreata were surgically removed. The specimen was placed in a siliconized 25 -mL Erlenmeyer flask with 5 $\mathrm{mL}$ of a $0.5 \%$ solution (wt/vol $15 \mathrm{mg} / 30 \mathrm{~mL}$ ) of type $V$ collagenase (Sigma Chemical Co.) diluted in cold HBSS. The pancreas was minced with scissors and incubated in a shaker-type water bath at $37^{\circ} \mathrm{C}$ for $8-10$ minutes. The pancreatic digest was poured into a black-backed petri dish, and islets were picked by hand. Typically, we purified $\sim 50$ islets per mouse.

Twenty medium-sized mouse islets per experiment were transferred to 75 -mm culture dishes in RPMI-1640 plus penicillin G $(100 \mathrm{U} / \mathrm{mL})$ and streptomycin $(100 \mu \mathrm{g} / \mathrm{mL})$, plus $10 \% \mathrm{FCS}$, plus $10 \mathrm{mM}$ HEPES, without glutamine, and cultured overnight.

Purification of mouse macrophages and macrophage studies. Mice were sacrificed with $\mathrm{CO}_{2}$ gas, and immediately, $10 \mathrm{~mL}$ of cold RPMI-1640 medium was injected into the peritoneal cavity under sterile conditions. The medium was aspirated out and the peritoneal cells were counted. Typically, we obtained $10^{6}$ macrophages per mouse and used $10^{5}$ macrophages per well. Peritoneal cells were pipetted into 96-well plastic dishes, and macrophages were purified by differential adherence over 1 hour. The cells were gently washed 3 times with DMEM $+0.1 \%$ FCS without indicator for nitrate/nitrite determination or with $\mathrm{HBSS}+\mathrm{Mg}^{2+}+\mathrm{Ca}^{2+}$ medium for superoxide determination.

For nitrate/nitrite, macrophages were stimulated with 2 $\mu \mathrm{g} / \mathrm{mL} \mathrm{LPS}+100 \mathrm{U} / \mathrm{mL}$ IFN- $\gamma$, and the medium was sampled at 48 hours. We used Griess reagent to detect nitrate/nitrite formation ( 1 part $1 \%$ sulfanilamide in $5 \%$ concentrated $\mathrm{H}_{3} \mathrm{PO}_{4}$ plus 1 part $0.1 \%$ naphthylethylenediamine dihydrochloride plus 2 parts conditioned medium) (15). A standard curve was generated for each experiment using sodium nitrate (Sigma Chemical Co.) in serial dilutions.

For superoxide measurement, we used a cytochrome $c$ assay that has been described previously $(16,17)$. Superoxide reduces ferricytochrome $c\left(\mathrm{Fe}^{3+}\right)$ to ferrocytochrome $c\left(\mathrm{Fe}^{2+}\right)$ and can be monitored spectrophotometrically at $550 \mathrm{~nm}$. Peritoneal cells, $\sim 10^{5}$ per well, were adhered into 96 -well plates and stimulated with $50 \mathrm{ng} / \mathrm{mL}$ PMA (Sigma Chemical Co.). Cytochrome c (160 $\mu \mathrm{M}$; Sigma Chemical Co.) was added to the macrophage preparation, and medium was sampled every 30 minutes. Medium containing cytochrome $c$ alone was used as a control and subtracted out from the absorbance readings of PMA-stimulated macrophages. The rate of $\mathrm{O}_{2}^{-}$production was estimated using a molar absorption coefficient of $21.1 /(\mathrm{mM} . \mathrm{cm})$.

Glucose-stimulated insulin secretion, nitrate/nitrite determination, and cytokine treatment. Twenty mouse islets per experiment were cultured overnight in 25 - $\mathrm{mm}$ dishes with $1.5 \mathrm{~mL}$ of RPMI- 1640 medium $/ 5 \mathrm{mM}$ glucose $+10 \%$ FCS $+10 \mathrm{mM}$ HEPES +100 $\mathrm{U} / \mathrm{mL}$ penicillin $\mathrm{G}+100 \mu \mathrm{g} / \mathrm{mL}$ streptomycin. The islet cultures were maintained at $37^{\circ} \mathrm{C}$ in a (Forma Scientific Inc., Marjetta, 
Ohio, USA) tissue culture incubator that provided an environment of $95 \% \mathrm{O}_{2} / 5 \% \mathrm{CO}_{2}$ gas. The next morning, islets were gently transferred to RPMI-1640 medium with $3 \mathrm{mM}$ glucose and incubated for 1 hour, at which time the medium was sampled for insulin measurement. The medium glucose concentration was then increased to $17 \mathrm{mM}$, and the islets were incubated for an additional hour. Once again, the medium was sampled for later insulin measurement. In certain experiments, we pretreated mouse islets with IL- $1 \beta(0.3 \mathrm{ng} / \mathrm{mL})+\mathrm{TNF}-\alpha(15 \mathrm{ng} / \mathrm{mL})+$ IFN- $\gamma(15 \mathrm{ng} / \mathrm{mL})$ for 18 hours overnight before measuring basal and glucose-stimulated insulin secretion.

For basal nitrate/nitrite determination, 40 medium-sized islets per well were incubated in a 96-well plate in $100 \mu \mathrm{L}$ DMEM (without indicator) $+5 \mathrm{mM}$ glucose $+0.1 \%$ FCS +10 $\mathrm{mM}$ HEPES $+100 \mathrm{U} / \mathrm{mL}$ penicillin $\mathrm{G}+100 \mu \mathrm{g} / \mathrm{mL}$ streptomycin. For cytokine-stimulated nitrate/nitrite determination, 40 medium-sized islets per well were treated as described above with the addition of IL- $1 \beta(0.3 \mathrm{ng} / \mathrm{mL})+$ TNF- $\alpha(15 \mathrm{ng} / \mathrm{mL})+$ IFN- $\gamma(15 \mathrm{ng} / \mathrm{mL})$ at time 0 . After 48 hours, $100 \mu \mathrm{L}$ of Greiss reagent was added to each well, and the absorbance was measured at $540 \mathrm{~nm}$ with a microtiter plate reader (Dynatech Laboratories, Chantilly, Virginia, USA).

12-HETE assay. One hundred mouse islets per experiment were incubated in $1.5 \mathrm{~mL}$ of RPMI- 1640 medium $+0.2 \%$ fatty acid-free BSA in the presence or absence of IL- $1 \beta(0.3 \mathrm{ng} / \mathrm{mL})$ + TNF- $\alpha(15 \mathrm{ng} / \mathrm{mL})+\operatorname{IFN}-\gamma(15 \mathrm{ng} / \mathrm{mL})$ for 1.5 hours at $37^{\circ} \mathrm{C}$. The islets and medium were extracted with $225 \mu \mathrm{L}$ cold ethanol ( $15 \%$ ethanol final concentration) and stored at $-70^{\circ}$ $\mathrm{C}$ for later 12-HETE determination. HETEs were extracted from the supernatant using C18 Bond Elut Columns (Varian Sample Preparations, Harbor City, California, USA). The samples in $15 \%$ ethanol were acidified to $\mathrm{pH} 3.0-3.5$ with $1 \mathrm{~N}$ $\mathrm{HCl}$. The Bond Elut columns were prepared by washing with methanol and water, and the samples were placed onto the columns by syringe. The HETEs were eluted with ethyl acetate and then quantified by RIA. This method has been validated by HPLC as described previously (18-20).

Statistics. Statistical analysis was performed with the GraphPad Instat program (GraphPad Software for Science Inc., San Diego, California, USA) for the PC. For 2 comparisons of all data, we applied the Student's $t$ test. All data are expressed as mean \pm SEM.

\section{Results}

12-LO KO mice are resistant to STZ-induced diabetes. Eight male 12 -LO KO mice and 12 male C57BL/6 mice received intraperitoneal injections of STZ $(40 \mathrm{mg} / \mathrm{kg})$ for 5 consecutive days between 0900 and 1000 hours. Fasting serum glucose was measured before the first injection and every 7 days thereafter. As seen in Figure 1, a statistically significant difference in mean serum glucose in the 2 groups is evident at 21 days (12-LO KO: $6.74 \pm 0.52$ $\mathrm{mM}$ vs. $\mathrm{C} 57 \mathrm{BL} / 6: 10.80 \pm 1.11 \mathrm{mM} ; P=0.01)$. By day 28 , the mean serum glucose for $12-\mathrm{LO} \mathrm{KO}$ mice vs. C57BL/ 6 mice was $7.24 \pm 0.43 \mathrm{mM}$ and $11.33 \pm 0.93 \mathrm{mM}$, respectively $(P=0.003)$. Therefore, disruption of the $12-\mathrm{LO}$ gene conferred resistance to STZ-induced diabetes. We also measured fasting serum insulin levels at each time point to assess in vivo residual $\beta$-cell function (Figure 2 ). C57BL/ 6 mice, despite similar glucose values before STZ injections, had statistically higher fasting insulin levels than did 12 -LO KO mice ( $164 \pm 7 \mathrm{nM}$ vs. $137 \pm 16 \mathrm{nM}$, respectively; $P=0.01)$. However, the serum insulin levels in C57BL/ 6 mice 28 days after STZ had decreased by $90 \%$ from baseline to $17 \pm 1 \mathrm{nM}$, whereas in the 12 - $\mathrm{LO} \mathrm{KO}$ mice, fasting insulin levels decreased only $45 \%$ to $75 \pm 4$

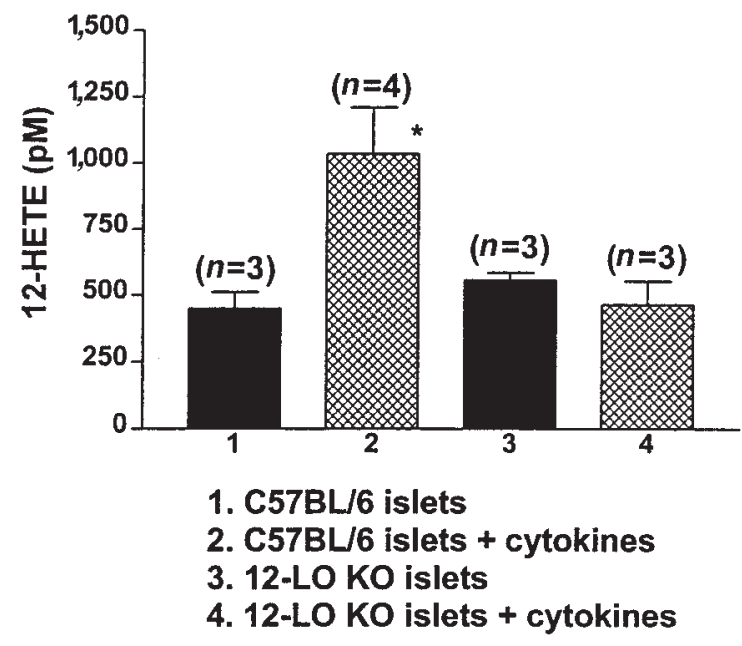

Figure 3

Differential effect of cytokines on 12-HETE production in C57BL/ 6 and 12-LO KO islets. C57BL/ 6 islets demonstrated a 2.5 -fold increase in 12HETE production in the presence of cytokines, whereas 12-HETE production in 12-LO KO islets was unchanged. The number in parenthesis represents the number of experiments performed for each condition. ${ }^{*} P$ $<0.05$ vs. C57BL/ 6 islets.

$\mathrm{nM}$. The insulin values in the C57BL/ 6 mice at 28 days were significantly lower than those in the 12 -LO KO mice $(P<0.0001$; Figure 2$)$.

12-HETE generation in C57BL/6 and 12-LO KO islets. We measured cytokine-induced 12-HETE production in islets to determine whether there was any functional 12LO protein in the 12-LO KO mice. One hundred islets per experiment were stimulated with the cytokines IL$1 \beta$, IFN- $\gamma$, and TNF- $\alpha$ for 1.5 hours at $37^{\circ} \mathrm{C}$. The islets were extracted into ethanol as described, and 12-HETE was measured. As seen in Figure 3, 12-LO KO islets did not generate 12-HETE in response to cytokine stimulation, whereas C57BL/6 islets produced a 2.5-fold increase, from $449 \pm 63 \mathrm{pM}$ to $1,035 \pm 175 \mathrm{pM}$. This suggests that a functional cytokine-inducible 12-LO enzyme is absent in 12-LO KO islets.

Assessment of insulin secretion, cytokine-induced inbibition of insulin secretion, and NO generation in C57BL/6 and 12LO KO islets. We purified islets from untreated C57BL/6 and $12-\mathrm{LO} \mathrm{KO}$ mice and measured basal $(3 \mathrm{mM})$ and glucose-stimulated insulin secretion. Both mouse strains showed identical basal (nonstimulated) and 17 $\mathrm{mM}$ glucose-stimulated insulin secretion (Figure 4). $12-\mathrm{LO} \mathrm{KO}$ and $\mathrm{C} 57 \mathrm{BL} / 6$ islets were subsequently exposed to cytokines, and glucose-stimulated insulin secretion was measured. Glucose-stimulated insulin secretion in cytokine-treated C57BL/6 islets decreased by $54 \%$ compared with untreated islets, whereas glucose-stimulated insulin secretion in 12 -LO KO islets decreased only $26 \%$ compared with untreated islets $(P<0.03$; Figure 5$)$. Therefore, elimination of a functional 12-LO enzyme in islets leads to resistance to cytokine-induced islet dysfunction. Furthermore, the 12-LO KO islet cytokine resistance was not related to $\mathrm{NO}$, as we found no difference in cytokine-stimulated nitrate/nitrite production (12-LO KO islets: $0.385 \pm$ 


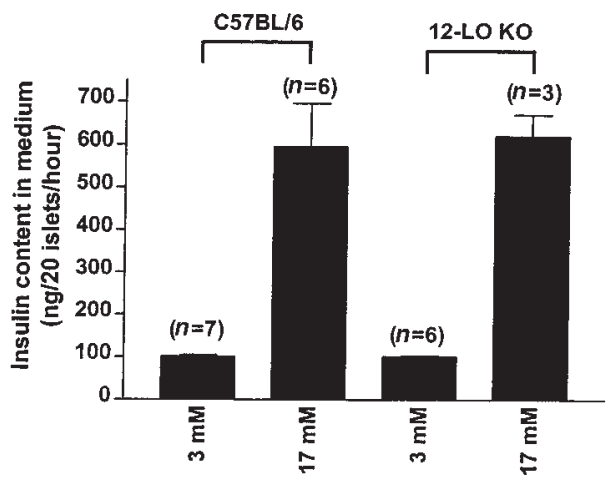

\section{Figure 4}

Basal and glucose-stimulated insulin secretion in 12-LO KO and C57BL/6 islets. Islet preparations were assessed for basal and glucose-stimulated insulin secretion as described in Methods. 12-LO KO islets secreted 102 $\pm 2 \mathrm{ng}$ insulin/20 islets/h in the basal state and $620 \pm 50 \mathrm{ng}$ insulin/20 islets/h when stimulated with $17 \mathrm{mM}$ glucose. In comparison, C57BL/6 islets secreted $102 \pm 4 \mathrm{ng}$ insulin/20 islets/h in the basal state and $595 \pm$ $101 \mathrm{ng}$ insulin/20 islets/h when stimulated with $17 \mathrm{mM}$ glucose. The number in parenthesis represents the number of experiments performed for each condition.

$0.125 \mathrm{nmol} / 40$ islets $/ 48 \mathrm{~h}, n=3$; C57BL $/ 6$ islets: $0.311 \pm 0.04 \mathrm{nmol} / 40$ islets $/ 48 \mathrm{~h}, n=4 ; P=0.55$ ).

Assessment of macrophage NO and superoxide production. Because 12-LO also is expressed in macrophages, we evaluated the possible alterations in macrophage function in 12-LO KO mice. Peritoneal macrophages were purified from $\mathrm{C} 57 \mathrm{BL} / 6$ and $12-\mathrm{LO} \mathrm{KO}$ mice, and studies were performed to determine whether they differed in $\mathrm{NO}$ and superoxide production. For NO generation, we used the Griess reagent to measure nitrate/nitrite from stimulated macrophages. Figure 6 demonstrates that LPS + IFN- $\gamma$ stimulation led to a 2 -fold- greater increase in NO production in C57BL/6 macrophages than in 12-

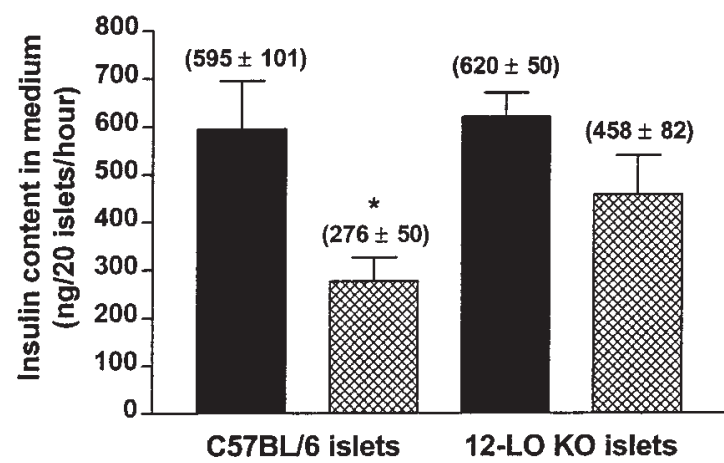

Figure 5

Effect of cytokine treatment on glucose-stimulated insulin secretion in $12-\mathrm{LO}$ KO and C57BL/ 6 islets. Isolated islets were subjected to high-dose cytokine treatment as shown. Filled bars represent $17 \mathrm{mM}$ glucose stimulation; hatched bars represent cytokine treatment $(0.5 \mathrm{ng} / \mathrm{mL}$ IL-1 $\beta$ + $30 \mathrm{ng} / \mathrm{mL}$ TNF- $\alpha+30 \mathrm{ng} / \mathrm{mL}$ IFN- $\gamma$ ) plus $17 \mathrm{mM}$ glucose stimulation. Cytokine treatment decreased glucose-stimulated insulin secretion by $26 \%$ and $54 \%$ in $12-\mathrm{LO}$ KO and C57BL/ 6 islets, respectively. Shown is 1 representative experiment in triplicate out of 3 separate experiments. ${ }^{*} P<0.03$ vs. C57BL/ 6 glucose-stimulated islets.
LO KO macrophages. In contrast, there was no difference in macrophage superoxide generation identified in the 2 mouse strains (Figure 7).

\section{Discussion}

It has been demonstrated previously that treatment of pancreatic islets with high-dose IL-1 $\beta$ can increase 12 -LO protein expression (9). Furthermore, IL- $1 \beta$ has been shown to increase 12-HETE levels in rat islets by increasing the availability of free arachidonic acid (AA) (10). Given that 12-LO activation leads to hydroperoxide generation in the form of 12-HPETE, it is possible that 12-LO inhibition could decrease lipid hydroperoxide formation in islets, protect islets from cytokine-induced dysfunction, and prevent cytotoxic damage induced by STZ. We have not determined whether 12-LO gene disruption alters STZ metabolism and thereby ameliorates STZ-induced diabetes by decreasing the concentration of STZ delivered to pancreatic $\beta$ cells. Nor have we formally identified whether the protective effect of 12-LO gene disruption on STZ-induced diabetes is through a pathway that prevents insulin secretory dysfunction rather than pancreatic $\beta$-cell apoptosis. However, when we performed immunohistochemistry on pancreatic sections taken from mice at 7-day intervals (data not shown), we observed preservation of islet size, number, and insulin content in 12-LO KO mice but significant decrease in these parameters in C57/BL6 mice. Therefore, the current data lend further support to the hypothesis that 12 -LO inhibition may preserve islet $\beta$-cell function, and identify $12-\mathrm{LO}$ as a potentially important enzyme that may be targeted for molecular inhibition.

Several studies also have addressed the question of whether lipoxygenase inhibitors can prevent pancreatic $\beta$-cell death. Zhou and colleagues recently demonstrated that thapsigargin-induced apoptosis in the MIN6 pancreatic $\beta$-cell line was significantly attenuated by lipoxygenase inhibitors. Furthermore, direct 12-HETE application in MIN6 cells reproduced the decrease in cell viability seen with thapsigargin (21). Earlier work by Rabinovitch and colleagues demonstrated that nordihydroguaiaretic acid, a lipoxygenase inhibitor, protected rat islets from cytokine-induced destruction (11). Others have demonstrated that lipoxygenase pathway products are activated in inflammatory disease states like inflammatory bowel disease (22), neuronal cells undergoing apoptosis (8), and human monocyte-mediated LDL oxidation (23). Therefore, lipoxygenase product generation may participate in a variety of inflammatory conditions.

Evidence also exists that lipoxygenase pathway products have a role in NO production. Kolb and colleagues demonstrated that nordihydroguaiaretic acid, a preferential lipoxygenase inhibitor, inhibited LPS-stimulated NO production in cultured macrophages in a dosedependent fashion $(24,25)$. Our data are consistent with this report in that stimulated macrophages from 12 -LO KO mice generated only $50 \%$ of the NO seen in similarly treated C57BL/6 macrophages. In contrast, AA metabolism does not seem to affect the production of superoxide by macrophages (15).

Conversely, it is tempting to speculate that high levels of NO may directly inhibit 12-LO enzyme activity through formation of iron-nitrosyl complexes similar to 
mitochondrial aconitase $(26,27)$, as 12 -LO is an ironcontaining enzyme (28). However, $\mathrm{Ma}$ and colleagues demonstrated that low-dose application of IL-1 $\beta$ (0.05 $\mathrm{ng} / \mathrm{mL}$ or less) to pancreatic islets increased 12-HETE formation through an NO-dependent mechanism (10), which would imply that NO formation did not inhibit 12-LO activity in these studies. They demonstrated that $\mathrm{NO}$ generation increased the available pool of AA (for subsequent metabolism by $12-\mathrm{LO}$ ) by inhibiting enzymes that reacylate AA into membrane phospholipid. Therefore, changes in intracellular $\mathrm{NO}$ concentration may be one factor that regulates 12 -LO product generation and, hence, modulates the redox state of the $\beta$ cell through the formation of 12-HPETE.

The precise mechanism by which leukocyte 12-LO inhibition may prevent cytokine-induced pancreatic $\beta$ cell cytotoxicity is likely to be complex. 12 -LO KO islets did have detectable levels of 12-HETE in the basal state; however, no appreciable increase in 12-HETE was evident after cytokine treatment. The presence of basal 12HETE may be due to release of esterified 12-HETE from membrane phospholipid via phospholipase $\mathrm{A}_{2}$ activation or through a yet uncharacterized isoform of 12-LO that is not induced by cytokines. Future studies will be necessary to clarify the mechanisms responsible for the basal 12-HETE in the 12-LO KO islets.

12-LO products also may act as intermediate signals in cellular inflammatory responses. 12-HETE can induce the stress-activated protein c-jun kinase (JNK) in islets and RIN m5F cells (29), and recent studies demonstrate that 12-HETE stimulates cAMP production in human fibroblasts (30). It is also possible that lipoxygenase products may activate certain forms of MAP kinases, including p38 MAP kinase, leading to downstream signaling effects.

In addition to generating hydroperoxides in pancreatic $\beta$ cells and acting as intracellular signals in inflammatory responses, numerous studies have defined the role of AA and lipoxygenase metabolites in nutrient- and glucose-stimulated insulin secretion in islets. AA stimulates insulin release in islets when calcium is removed from the medium (because calcium chelates AA). Insulin secretion was independent of further AA metabolism by lipoxygenase enzymes, as it was not prevented by lipoxygenase inhibitors (31). Treatment of rat islets with $p$-hydromercuribenzoic acid, an inhibitor of arachidonylCoA synthase and/or lysophos-phatidyl/acyl-CoA transferase (32), prevented reacylation of lysophospholipids with $\mathrm{AA}$, resulting in insulin release at $1.7 \mathrm{mM}$ glucose and potentiation of insulin release at $16.7 \mathrm{mM}$ glucose (33). These data suggest that reacylation of fatty acids such as AA and/or 12-HETE into membrane phospholipid may play a critical role in insulin secretion. AAinduced insulin release from islets was blunted by pretreatment with phorbol ester, indicating that protein kinase $\mathrm{C}$ may be part of this metabolic pathway. In addition, indomethacin, a cyclooxygenase inhibitor, potentiated AA-induced insulin release (34).

Additional studies showed that $12-\mathrm{LO}$ plays a role in glucose-stimulated insulin secretion $(34,35)$. Pretreatment of islets with LO inhibitors caused attenuation of glucose-stimulated insulin secretion, but the hydroperoxy product 12-HPETE was capable of stimulating

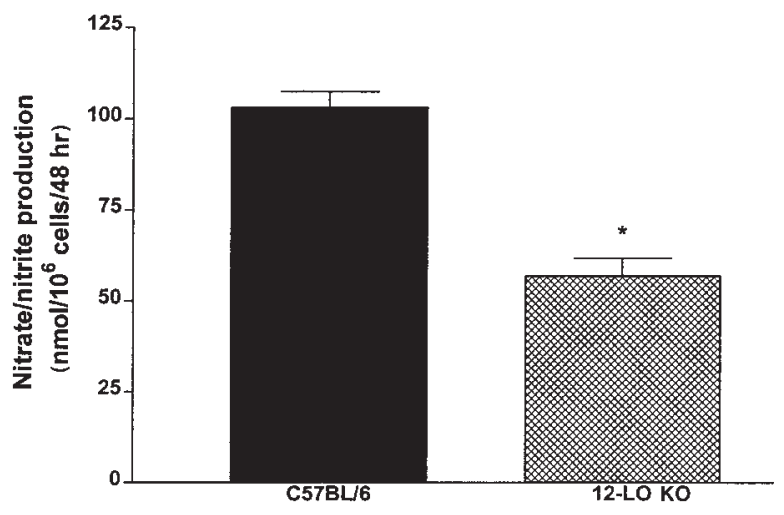

Figure 6

Nitrate/nitrite determination in 12-LO KO and C57BL/6 peritoneal macrophages. Peritoneal macrophages were purified as described in Methods and stimulated with LPS $(2 \mu \mathrm{g} / \mathrm{mL})+\mathrm{IFN}-\gamma(100 \mathrm{ng} / \mathrm{mL})$ for 48 hours. We used Griess reagent to measure total medium nitrate/nitrite as an estimate of NO production. As shown, 12-LO KO macrophages generated $\sim 50 \%$ of the $\mathrm{NO}$ of $\mathrm{C} 57 \mathrm{BL} / 6$ macrophages under the conditions described. Six individual experiments were performed with macrophages isolated from both strains of mice. ${ }^{*} P<0.0001$ vs. C57BL/ 6 macrophages.

insulin release. However, AA produced a greater increase in insulin release than 12-HPETE. 12-HPETE in doses ranging from $0.05 \mu \mathrm{g} / \mathrm{mL}$ to $1 \mu \mathrm{g} / \mathrm{mL}$ induced a 1.5 -fold increase in glucose-stimulated $(300 \mathrm{mg} / \mathrm{dL})$ insulin release, whereas AA $(5 \mu \mathrm{g} / \mathrm{mL})$ induced a 2 -fold increase (36). 12-HETE did not alter glucose-stimulated insulin secretion in these experiments. Glucose- and AA-stimulated insulin release was further enhanced by diethylmalate, an agent that binds reduced glutathione and leads to accumulation of fatty acid hydroperoxides like 12-HPETE and epoxides.

The current results suggest that inhibition of 12-LO enzyme activity in islets does not appreciably alter basal

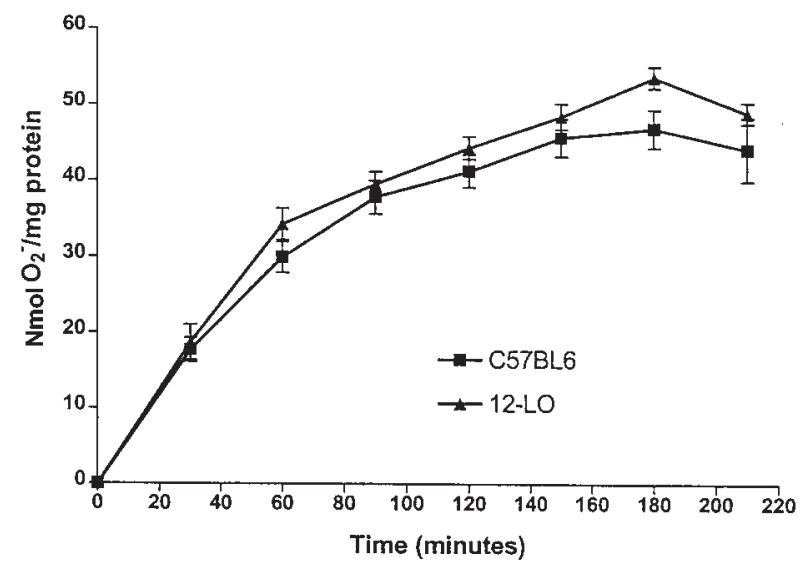

Figure 7

Generation of superoxide by 12 -LO KO and C57BL/ 6 macrophages. Purified macrophages were treated with PMA $(50 \mathrm{ng} / \mathrm{mL})$, and superoxide generation was measured by monitoring the reduction of ferricytochrome $c$ to ferrocytochrome $c$ at $550 \lambda$ over time. As shown, no difference was observed in superoxide generation. Eight individual experiments were performed with macrophages isolated from both strains of mice. 
or glucose-stimulated insulin secretion. These data support previous studies showing that AA has the predominant effect on insulin secretion, whereas 12 -LO products play a lesser role. Because inhibition of 12-LO does not appear to affect the overall stimulus-secretion coupling mechanism between glucose and insulin, it is possible that the 12-LO pathway provides fine tuning for AA-mediated insulin secretion.

In conclusion, 12-LO gene disruption significantly prevents STZ-induced diabetes through mechanisms that decrease pancreatic $\beta$-cell damage and reduce macrophage NO production. These results suggest that inhibition of leukocyte 12 -LO in pancreatic $\beta$ cells may be an effective approach to prevent cytokine-induced cytotoxicity in models of type 1 diabetes and islet transplantation rejection.

\section{Acknowledgments}

This work was supported in part by the Iacocca Foundation, a Juvenile Diabetes Foundation (JDF) Fellowship (to S. Chen), and a JDF Research Award (to J.L. Nadler and D. Bleich). Additional support was obtained from the National Institutes of Health (NIH), the JDF (PPG HL-55798), and NIH grant HL53558 (to C.D. Funk).

1. Bleich, D., Chen, S., Gu, J-L., and Nadler, J.L. 1998. The role of 12-lipoxygenase in pancreatic $\beta$-cells. Int. J. Mol. Med. 1:265-272.

2. Turk, J., Colca, J., Kotagal, N., and McDaniel, M. 1984. Arachidonic acid metabolism in isolated pancreatic islets. I. Identification and quantitation of lipoxygenase and cyclooxygenase products. Biochim. Biophys. Acta. 794:110-124.

3. Turk, J., Colca, J., and McDaniel, M. 1984. Arachidonic acid metabolism in isolated pancreatic islets. III. Effects of exogenous lipoxygenase products and inhibitors on insulin secretion. Biochim. Biophys. Acta. 834:23-36.

4. Turk, J., et al. 1985. Arachidonic acid metabolism in isolated pancreatic islets. IV. Negative ion mass spectrometric quantitation of monooxygenase product synthesis by liver and islets. Biochim. Biophys. Acta. 835:1-17.

5. Turk, J., Wolf, B.A., Easom, R.A., Hughes, J.H., and McDaniel, M.L. 1989. Arachidonic acid metabolism in isolated pancreatic islets. V. The enantiomeric composition of 12 -hydroxy- $(5,8,10,14)$-eicosatetraenoic acid indicates synthesis by a 12-lipoxygenase rather than monooxygenase. Biochim. Biophys. Acta. 1001:16-24.

6. Turk, J., et al. 1988. Arachidonic acid metabolism and insulin secretion by isolate human pancreatic islets. Diabetes. 37:992-996.

7. Shannon, V.R., Ramanadham, S., Turk, J., and Holtzman, M.J. 1992. Selective expression of an arachidonate 12-lipoxygenase by pancreatic islet beta cells. Am. J. Physiol. 263:E908-E912.

8. Li, Y., Mahler, P., and Schubert, D. 1997. A role for 12-lipoxygenase in nerve cell death caused by glutathione depletion. Neuron. 19:453-463.

9. Bleich, D., et al. 1995. Interleukin 1- $\beta$ regulates the expression of a leukocyte type of 12-lipoxygenase in rat islets and RIN m5F cells. Endocrinology. 136:5736-5744.

10. Ma, Z., et al. 1996. Interleukin-1 enhances pancreatic islet arachidonic acid 12-lipoxygenase product generation by increasing substrate availability through a nitric oxide-dependent mechanism. J. Biol. Chem. 271:1029-1042

11. Rabinovitch, A., Baquerizo, H., and Sumoski, W. 1990. Cytotoxic effects of cytokines on islet $\beta$-cells: evidence for involvement of eicosanoids. Endocrinology. 126:67-71.

12. Mendola, J., Wright, J.R., and Lacy, P. 1989. Oxygen free-radical scavengers and immune destruction of murine islets in allograft rejection and multiple low-dose streptozotocin-induced insulitis. Diabetes. 38:379-385.

13. Takasu, N., Koniya, I., Asawa, T., Nagasawa, Y., and Yamada, T. 1991.
Streptozotocin and alloxan-induced $\mathrm{H}_{2} \mathrm{O}_{2}$ and DNA fragmentation in pancreatic islets. Diabetes. 40:1141-1145.

14. Sun, D., and Funk, C.D. 1996. Disruption of 12/15 lipoxygenase expression in peritoneal macrophages. Enhanced utilization of the 5-lipoxygenase pathway and diminished oxidation of low density lipoprotein. J. Biol. Chem. 271:24055-24062.

15. Green, L.C., et al. 1982. Analysis of nitrate, nitrite, and $\left({ }^{15} \mathrm{~N}\right)$ nitrate in biological fluids. Anal. Biochem. 126:131-138.

16. Schultz, R.M., Nanda, S.K.W., and Altom, M.G. 1985. Effects of various inhibitors of arachidonic acid oxygenation on macrophage superoxide release and tumoricidal activity. J. Immunol. 135:2040-2044.

17. Bromberg, Y. and Pick, E. 1983. Unsaturated fatty acids as second messengers of superoxide generation by macrophages. Cell. Immunol. 79:240-252.

18. Gu, J-L., et al. 1994. Evidence that a leukocyte type of 12-lipoxygenase is expressed and regulated by angiotensin II in human adrenal glomerulosa cells. Endocrinology. 134:70-77.

19. Nadler, J.L., Natarajan, R., and Stern, N. 1987. Specific action of the lipoxygenase pathway in mediating angiotensin II-induced aldosterone synthesis in isolated adrenal glomerulosa cells. J. Clin. Invest. 80:1763-1769.

20. Natarajan, R., Gonzales, N., Lanting, L., and Nadler, J.L. 1994. Role of the lipoxygenase pathway in angiotensin II-induced vascular smooth muscle cell hypertrophy. Hypertension. 23(Suppl. I):I142-I147.

21. Zhou, Y-P., et al. 1998. Apoptosis in insulin-secreting cells. Evidence for the role of intracellular $\mathrm{Ca}^{2+}$ stores and arachidonic acid metabolism. $J$. Clin. Invest. 101:1623-1632.

22. Shannon, V.R., Stenson, W.F., and Holtzman, M.J. 1993. Induction of epithelial arachidonate 12-lipoxygenase at active site of inflammatory bowel disease. Am. J. Physiol. 264:G104-G111.

23. Folcik, V.A., and Cathcart, M.K. 1993. Assessment of 5-lipoxygenase involvement in human monocyte-mediated LDL oxidation. J. Lipid Res. 34:69-79

24. Imai, Y., Kolb, H., and Burkart, V. 1993. Nitric oxide production from macrophages is regulated by arachidonic acid metabolites. Biochem. Biophys. Res. Commun. 197:105-109.

25. Kroncke, K.D., Rodriguez, M.I., Kolb, H. and Kolb-Bachofen, V. 1993. Cytotoxicity of activated rat macrophages against syngeneic islet cells is arginine-dependent, correlates with citrulline and nitrite concentrations and is identical to lysis by the nitric oxide donor nitroprusside. Diabetologia. 36:17-24.

26. Corbett, J.A., Lancaster, J.R., Sweetland, M.A., and McDaniel, M.L. 1991. Interleukin- $1 \beta$-induced formation of EPR-detectable iron-nitrosyl complexes in islets of Langerhans. J. Biol. Chem. 266:21351-21354.

27. Wiesner, R., et al. 1996. Nitric oxide oxidises a ferrous mammalian lipoxygenase to a pre-activated ferric species. FEBS Lett. 389:229-232.

28. Matsuda, S., Suzuki, H., Yoshimoto, T., Yamamoto, S., and Miyatake, A. 1991. Analysis of non-heme iron in arachidonate 12-lipoxygenase of porcine leukocytes. Biochim. Biophys. Acta. 1084:202-204.

29. Bleich, D., Chen, S., Wen, Y., and Nadler, J.L. 1997. The stress-activated cjun protein kinase (JNK) is stimulated by lipoxygenase pathway product 12-HETE in RIN m5F cells. Biochem. Biophys. Res. Commun. 230:448-451.

30. Ueki, S., Takagi, J., Kobayashi, Y., Sato, F., and Saito, Y. 1999. 12-hydroxy$5 Z, 8 Z, 10 \mathrm{E}, 14 \mathrm{Z}$, eicosatetraenoic acid (12-HETE) stimulates cAMP production in normal human fibroblasts. J. Cell Pbysiol. 178:63-68.

31. Metz, S. 1989. Blockade by lipoxygenase inhibitors of Ca2+-dependent insulin secretion from permeabilized rat islets. Biochem. Pharmacol. 38:1849-1862.

32. Kroner, E.E., Peskar, B.A., Fischer, H., and Ferber, E. 1981. Control of arachidonic acid accumulation in bone marrow-derived macrophages by acyltransferases. J. Biol. Chem. 256:3690-3697.

33. Metz, S.A. 1986. p-Hydroxymercuribenzoic acid inhibits arachidonic acid esterification into two distinct pools and stimulates insulin release in intact rat islets. J. Pharmacol. Exp. Ther. 238:809-818.

34. Metz, S., VanRollins, M., Strife, R., Fujimoto, W., and Robertson, R.P. 1983. Lipoxygenase pathway in islet endocrine cells. J. Clin. Invest. 71:1191-1205.

35. Laychock, S.G. 1985. Effects of hydroxyeicosatetraenoic acids on fatty acid esterification in phospholipids and insulin secretion in pancreatic islets. Endocrinology. 117:1011-1019.

36. Metz, S.A., Murphy, R.C., and Fujimoto, W. 1984. Effects on glucoseinduced insulin secretion of lipoxygenase-derived metabolites of arachidonic acid. Diabetes. 33:119-124. 